This item was submitted to Loughborough's Research Repository by the author.

Items in Figshare are protected by copyright, with all rights reserved, unless otherwise indicated.

\title{
Normalizing post adoption support for all
}

PLEASE CITE THE PUBLISHED VERSION

https://doi.org/10.1111/cfs.12391

\section{PUBLISHER}

(c) Wiley

\section{VERSION}

AM (Accepted Manuscript)

\section{PUBLISHER STATEMENT}

This work is made available according to the conditions of the Creative Commons Attribution-NonCommercialNoDerivatives 4.0 International (CC BY-NC-ND 4.0) licence. Full details of this licence are available at: https://creativecommons.org/licenses/by-nc-nd/4.0/

\section{LICENCE}

CC BY-NC-ND 4.0

\section{REPOSITORY RECORD}

Lushey, Clare, Lisa Holmes, and Samantha McDermid. 2019. "Normalizing Post Adoption Support for All". figshare. https://hdl.handle.net/2134/26210. 


\section{Abstract}

Within a context of substantial adoption policy reform in England this paper explores post adoption support. Findings from a small scale survey of 22 local authorities in England and interviews with 11 adoption practitioners (from 11 of the authorities that completed the survey), are presented and related national policy discussed. The paper argues that support should continue post-matching a child with their adoptive parent(s) and that this should be the norm rather than the exception. It also emphasises the need to improve the availability of, and access to post adoption support in a timely manner.

\section{Introduction}

Why is post adoption support needed?

Due to their pre-care experiences many children will require on-going support following placement with their adoptive parent(s). In England in the year ending 31 March 2016, 4,690 children were adopted and 70\% of these children had been removed from their birth parents due to abuse or neglect (Department for Education, 2016b). Consequently many adopted children will have complex emotional, behavioural and developmental needs arising for some time after the child has been adopted (Rushton, 2003; Neil et al., 2010; Pennington, 2012).

\section{Adoption policy reform}

Over the last five years there has been an emphasis on adoption reform in England and as part of this reform the government introduced a package of reform measures aimed at improving adoption support. This includes An Action Plan for Adoption: Tackling Delay (Department for Education 2012a), Supporting Families that Adopt (Department for Education 2012b), Further Action on Adoption: Finding More Loving Homes (Department for Education, 2013), the Adoption Support Fund (ASF) and Regional Adoption Agencies.

An Action Plan for Adoption: Tackling Delay set out the government's plan to improve the system of adoption in England through proposing to reduce delays in the adoption process and improving the recruitment, assessment and preparation of 
prospective adopters. The plan was created due to concerns about the amount of time it took for a child to be adopted from care with research showing that the average waiting time between coming into care and being placed with their adoptive parents is twenty one months (Department for Education 2012a). Reportedly due to an adoption process that was not conducive to encouraging prospective adopters or conducting assessments and preparation of adopters in a timely manner. Research evidence used showed that delays in decision making could have lasting long-term effects on the wellbeing of children and financial consequences. In addition to this, national data suggested that the numbers of children under five coming into care were going up but that the number of adoptions taking place was reducing despite adoption being seen as the best option for children, particularly young children, as it has the potential to provide stability and permanency (Department for Education 2012a). Supporting Families that Adopt aims to give adoptive parents equal treatment to that of birth parents and more access to support through ensuring adopters are treated fairly, being clear about adoptive parents' rights, providing specialist support when adoptive families need it, and raising standards and improving practice. It was developed amid concerns that research shows that adoptive parents are often left without the support that they and their adoptive child needs (Department for Education 2012b).

More recently, in May 2015, the Government established a new Adoption Support Fund (ASF) worth £19.3 million over two years. In 2013, the Department for Education (DfE) published Further Action on Adoption: Finding More Loving Homes which sets out their plans to recruit more adopters and improve support available to adoptive families. It led to the implementation of the Prototype ASF. The fund is to help adoptive families access support following adoption, through paying for therapeutic support (Department for Education, 2015a). This was introduced due to recognition of the need to improve therapeutic support for adopted children and their families in order to address trauma experienced during childhood. The government increased the ASF in $2016 / 17$ to $£ 21$ million and $£ 28$ million in $2017 / 18$, with further increases planned for subsequent years in this Parliamentary period (Department for Education, 2016a). In 2017 the Department for Education introduced a 'fair access limit' of $£ 5,000$ per child for the ASF and asked LAs to share the costs of support over and above that limit through a matched-funding approach. This was introduced 
due to the realisation that continuing to operate the ASF with no limits in place was unsustainable. Early findings suggest that the ASF has enhanced adoptive families' access to therapeutic support and been vital in preventing adoption breakdowns (Lewis and Ghate, 2015).

As well as additional funds the government plans to introduce Regional Adoption Agencies. Under the scheme LAs are expected to join up with other LAs and voluntary adoption agencies (VAAs) to develop 'Regional Adoption Agencies'. The key intended purpose of these agencies is to ensure that social workers have immediate access to a greater number of adopters, and a wider array of support services that are more accessible to adopted children and their families (see Department for Education, 2015b for further details). The Regional Adoption Agencies were created for a number of reasons. The system being fragmented geographically is one of them - with many LAs and VAAs only having access to a small pool of potential adopters from their region. Other reasons include an over emphasis on using adopters approved in-house before approaching other LAs and VAAs resulting in children waiting longer to be adopted and regional gaps in the types of adoption support services on offer (Department for Education, 2015b).

\section{Post adoption assessments and support}

Local authorities are required to undertake an assessment of need for post adoption support should it be requested by an adoptive family, however they are not obligated to provide post adoption services. Pennington (2012) revealed that adoptive parents are often not aware of their right (under the Adoption and Children Act, 2002) to request an assessment for adoption support services, with 64\% revealing that they had not been informed of this entitlement. In addition, Pennington (2012) found that despite the fact that LAs in England are legally required to undertake an assessment of need, some adoptive parents' requests for such an assessment were not carried out; some were outright refused an assessment and others requests were ignored.

Post adoption support available for adopted children and their families in England takes many forms, e.g. therapeutic services, educational support, financial assistance, peer support groups. Only a small number $(n=12)$ of studies have explored services available to adoptive children and their the families in England 
(see Stock et al., 2016; Selwyn et al., 2014; Biehal et al. 2010; Bonin et al. 2013; Cooper \& Johnson 2007; Harris, 2004; Pennington 2012; Randall 2009; Rushton \& Dance 2002; Rushton \& Monck 2009; Selwyn et al. 2006a; Sturgess \& Selwyn 2007). The results vary but on the whole families appear to have more access to low level support, e.g. letterbox schemes rather than higher level support such as therapeutic services. The reasons for this are unclear. Sturgess and Selwyn (2007) found that adopters' satisfaction with services is mixed and over half (58\%) of adopters describe feeling inadequately supported, at some point, since their child was placed.

\section{Aims and objectives}

This paper explores post adoption support in England. The following sections of this paper focus on a study, undertaken in 2012, that explored the provision of post adoption support in England within the timeframe of substantial policy reform. It focuses on requests from adoptive families for an assessment of needs and support available - exploring strengths and limitations and discussing the findings in relation to adoptive policy reform.

The aims of the study were to explore how post adoption support teams and services are structured and to identify barriers and facilitators to effective provision. The objectives were to:

- Explore requests for assessments for post adoption support and factors that hinder and support quality assessments;

- Identify the availability of post adoption support;

- Explore what local authorities perceive to be the main barriers to the provision of post-adoption support services.

\section{Methodology}

A mixed methods approach was adopted whereby an online survey was distributed to a sample of local authorities (LAs) in England and interviews undertaken with Children's Social Care (CSC) practitioners. Mixed methods research combines qualitative and quantitative research approaches for the purposes of breadth and depth of understanding and corroboration (Johnson et al., 2007). A mixed methods approach was adopted because the survey data provided the opportunity to obtain 
quantitative data and the semi structured interviews the means to explore contextual issues and factors in more detail. A mixed-method design expands the research and makes it more comprehensive, i.e. there is more information from which to draw conclusions.

\section{Ethics}

Ethical approval was obtained from Loughborough University's Ethics Approvals (Human Participants) Sub-Committee and written informed consent obtained prior to completion of the surveys and interviews. The research adhered to Loughborough University's Ethics Approvals (Human Participants) Sub-Committee 'code of practice on investigations involving human participants'. All data were anonymised as soon as possible after collection. Participants were assigned a unique identification number and data was stored against this number rather than against the names of the participants. Data were stored in a locked filing cabinet and/or in an encrypted form on the computer.

\section{Survey}

An online survey, was distributed to a stratified sample of 50 LAs in England. The survey questions were devised to explore the assessment process, determine services available to adopted children and their families and explore what local authorities perceive to be the main barriers to the provision of post-adoption support services. The survey included questions about: the structure of their adoption team; routinely collected data on adopted families; when parents are likely to request an assessment for post adoption support; factors that support or hinder the completion of quality assessments; post adoption support available; and most frequently requested support. The survey included a mixture of closed and open questions. Open ended questions were used when deemed necessary, in this case, where the research team wanted to give the respondent the opportunity to give a free text answer and not restrict them to a limited set of options. The interview guide included open ended questions only and explored additional areas to those covered in the survey. The interview guide provided the research team with the opportunity to obtain an in-depth meaningful answer and to probe to obtain further information where necessary. 
Twenty two individuals from 22 English LAs responded to the online survey (44\% response rate). Four authorities completed the survey anonymously, that is, the representative respondent did not state which LA they were from. In just over two thirds $(n=15)$ of authorities the survey was completed by an adoption team or service manager, in about a quarter $(n=5)$ it was completed by an adoption worker, the remaining two were completed by a practice consultant and administrator, respectively.

\section{Local authority type and region}

Eighteen provided the name of their local authority (LA). Of these 18, the most common type of authority was unitary $(n=8,44.4 \%)$, followed by county $(n=5,27.8 \%)$, London Borough $(n=4,22.2 \%)$ and metropolitan $(n=1,5.6 \%)$. Surveys were completed by LAs spread across England, as table 1 below shows.

Of the authorities that provided the name of their $L A(n=18), 50 \%(n=9)$ are ranked in the top 25\% for indicator A3 (percentage of children who wait less than 21 months between entering care and moving in with their adoptive family). Of the remaining nine, six are in the middle $50 \%$ and three are ranked in the lowest $25 \%$. For indicator A4 (percentage of adoptions from care), the majority $(61.1 \%, n=11)$ are ranked in the middle $50 \%$.

\section{Interviews}

The research team carried out 11 in-depth telephone semi-structured interviews with a sub sample of the English LAs. Telephone interviews provide extended geographical access, saves on time and costs in terms of travel (Miller, 1995), and enhances the opportunity to access hard to reach populations such as those that may find it difficult to commit to a face-to-face interview due to work commitments (Creswell, 1998). However there are concerns that telephone interviews restrict the rapport (Shuy, 2003).

All the authorities were invited to participate in a telephone interview and interviews were arranged with all authorities that expressed an interest in taking part, except in the authorities where the potential participant was not available during the fieldwork 
timeframe. Interviews were conducted with seven adoption managers, three adoption support managers and one head of an adoption and fostering service.

The aims of the interviews were to explore the key issues for the LAs that impact on the provision of post adoption support. Semi structured interviews were undertaken and the questions covered the following areas:

- The availability of post adoption support services and their effectiveness;

o Services available

o Recent changes in the availability of services and/or changes in thresholds for service provision

o How effective the services were perceived to be

o Gaps in service provision

- Assessments of need:

o What services are most commonly requested by adopters (preplacement)

o What needs are most commonly identified during the assessment process

o Most common reasons why families request an assessment of need and what support do they most commonly seek

\section{Analysis}

Interview data were exported into the Nvivo software package and thematic analysis was undertaken to identify patterns through a rigorous process of data familiarisation, data coding and theme development. A deductive approach was undertaken whereby data coding and theme development were directed by the research questions. Quantitative data from the survey were analysed in Excel using descriptive analyses. The sample size was too small to undertake analysis of statistical significance.

The survey data explored specific topic areas (e.g. the assessment process, services available to adopted children and their families, barriers to the provision of post-adoption support services) and analysis was directed by these. The interviews however, as well as exploring these areas, provided the opportunity to ascertain issues that may not have been identified otherwise due to all questions being open 
ended which meant the respondent was not restricted to pre-define answers. As such the majority of sections include data from the survey and interviews except for the last section on 'lack of resources for service provision' section which was an issue identified by a number of respondents during interviews only.

\section{Limitations}

A limitation of the study was the relatively small sample size. The timeframe (the study was undertaken over a short timescale of six weeks to provide findings to inform the adoption reform agenda) limited the amount of time to recruit a larger sample size and a larger data set. Whilst small studies can yield results quickly the findings need careful interpretation as it is not possible to make strong conclusions. Those completing the surveys were given the opportunity to liaise with their colleague to gather information, however whether or not this took place cannot be guaranteed and this needs to be taken into consideration when interpreting the findings. The findings are however consistent with the wider literature.

There is some missing data where the respondents chose not to answer a question. Missing data reduce the representativeness of the sample and can distort inferences made. However, the amount of missing data is minimal and the research team are confident that that there is little or no bias, or distortion in the conclusions drawn from this study.

Survey respondents had the opportunity to provide more than one response for one question, at times, due to the inclusion of three statements and a Likert scale of: very often, often, occasionally, rarely and never. The implication is that the participant is not required to provide a yes or no answer but allows them to respond in a degree of agreement. However, questions have been raised about whether the number of categories on a scale influences the responses given (Kieruj and Moors, 2010) and the extent to which answering a scale means the respondents do not have make a yes or no decision and effectively take a stance on an issue. 


\section{Results}

The survey and interview data are presented together below and hence it includes the findings from the survey of 22 participants and interviews with the 11 practitioners - both from the same 22 local authorities (LAs).

Assessment of needs

\section{$\underline{\text { Requesting an assessment }}$}

Survey respondents were asked to specify when adoptive families were likely to request an assessment of need for post adoption support. Results from the survey suggest that it was common for families to request an assessment at crisis point (i.e. when the adoption was at risk of breakdown), with $73 \%\left(n=14\right.$ out of $\left.19^{1}\right)$ of LAs stating that families 'very often' or 'often' request an assessment at this stage. The majority $\left(88.9 \%, n=16\right.$ out of $18^{2}$ ) of respondents reported that families only 'occasionally' or 'rarely' request an assessment in response to advice from a partner agency and only two fifths of practitioners stated that families $\left(42.1 \%, \mathrm{n}=8\right.$ out of $\left.19^{3}\right)$ will 'very often' or 'often' request an assessment when difficulties first emerge. The scale allowed respondents to select more than one answer but rate their agreement with the statement. See table 2 below for further details:

Two interviewees suggested that families will often approach their authority as a last resort, when all other sources of support have been exhausted. One interviewee stated that it was uncommon for adoptive parents to request an assessment for post adoption support, instead adopters contacted the adoption service stating that they can no longer cope' and it is at this stage that an assessment of need would be suggested. Interviewees suggested that in some cases parents felt that they would be perceived as failures by agencies if they asked for support:

Part of it's 'I'm not coping with this very well but I don't want to admit it because I've just been through this assessment process' which is huge and 'I sure don't want to admit that I'm having difficulties' (Interviewee one).

\footnotetext{
${ }^{1}$ Data was missing for three respondents.

2 Data was missing for four respondents.

${ }^{3}$ Data was missing for three respondents.
} 
It tends to be harder for people to come to us for help. And of, course they are anxious, we are part of social services, they worry about child protection issues and so on and so forth. And of, course it is difficult to admit that you need help. I think it is quite difficult to make that call (Interviewee two).

To address these types of concerns, just over a third of the interviewees $(n=4)$ reported 'normalising' the need for support:

Our bottom line [with prospective adopters] is that adoption will have its challenges and we need to be ready to help people. We don't see asking for help as a sign of weakness, but a sign of a good adopter who wants to do the best for their child, so we promote that model (Interviewee three). We normalise the fact that you will need support, its fine. You can come back to us (Interviewee four).

Two interviewees reported that where good systems of on-going support were in place throughout the adoption process, fewer assessments for post adoption support were required, because families were already in receipt of services to meet their needs. One interviewee noted:

I am sure that we are underreporting [the support offered to children and families] compared to other areas because we have a good system of continuity, but because we don't close the file at the point of an order and hand over to a separate adoption team, then we don't have a clear break (Interviewee four).

Furthermore, five interviewees reported that where possible, post adoption support is considered to be a continuation of the support provided as a result of the adoption plan.

It was highlighted that some parents may never make contact with their local authority for support once the child has been placed and an adoption order made, simply because they wish to take on the responsibility of caring for their child without social services involvement: 
What happens at the time is that you get two pieces of paper and the adoption [is granted] and the child is placed and the adoption order is made and for $80 \%$ of the people [adoptive parents] are quite happy [to go away and cease all involvement with their local authority] (Interviewee five).

One interviewee suggested that as time passes parents are not always aware of where to go for support should they require it:

Once they've got the order everything falls away and they try and do it themselves. The reason they don't call back is because they don't know who to call (Interviewee one).

To summarise this study found that parents rarely requested an assessment for post adoption support needs when issues first arose and instead delayed until they were no longer able to cope. Practitioners interviewed suggested normalising support to address this issue, through ensuring that support, post adoption, is continued and that this is standard practice, instead of local authorities ceasing involvement at the point of adoption.

\section{Factors that support or inhibit the quality of assessments}

The survey respondents were asked to identify any factors that supported or inhibited the completion of quality assessments for post adoption support in England. The main issues identified were lack of capacity in the adoption and post adoption team, lack of resources and having specialist knowledge and expertise (see table 3 for further details). The capacity of those completing assessments of needs; was identified by just over one third of the survey respondents ( $n=8$ out of 22). One respondent reported:

There is little capacity in my team to meet the demand of the number of adopters seeking support (Survey respondent one).

The specialist knowledge and expertise of adoption team workers was identified by four respondents as a key factor that facilitates the completion of quality assessments by both survey respondents and interviewees. The issue was summarised by a survey respondent: 
Quality assessments require social workers with specialist knowledge of the complexities of children who have experienced trauma and the impact this has had on their brains, development, behaviour and on those caring for them. This knowledge and understanding is sometimes lacking in other professionals which can inhibit a shared view of the issues/solutions (Survey respondent two).

Whilst training and where families move areas were only issues raised by one respondent each the four interviewees suggested that specific training provided to other professionals working with adopted children and families could improve the quality of both assessments and the subsequent support provided to adopted children and their families. Three interviewees reported that the quality of assessments may be inhibited where the family is not previously known to a team, i.e. they have moved to a new area:

Those families can just come up out of the blue and we can have no knowledge of them and that is really difficult in order to know what services you need to provide, you know, it's not possible to plan very well (Interviewee six).

In summary, this study identified that the following factors hindered post adoption support: lack of capacity in the adoption and post adoption team, lack of resources and having specialist knowledge and expertise. Factors facilitating post adoption support were identified as specialist knowledge and expertise and training provided to other professionals working with adopted children and families

\section{Availability of post adoption support}

Survey respondents were asked to detail the adoption support services available in their LA area. Three hundred and eleven services were identified across the 22 authorities. The services available were wide ranging and varied from lower intensity support such as 'peer support groups' to higher level 'therapeutic support'. The most common support service available to adopted children and their families was counselling with 38 services, followed by general advice and information identified across 22 authorities. The least available service was short breaks (formerly known 
as respite services), for adoptive families, with only 13 short break services identified. See table 4 for further details.

Survey respondents were also asked to identify which three services were most frequently requested by adoptive families. Twenty one respondents provided this information. As presented in table 5 the most commonly requested services were CAMHS $(n=12)$ and general advice and information $(n=12)$

Whilst the survey did not explore the availability of post adoption services, i.e. accessibility, waiting times, costs etc. interviews with practitioners revealed that the services that were most frequently requested by families were also reportedly the services where there were the biggest gaps in service provision, i.e. CAMHS and therapeutic services, and educational support. Survey respondents were asked what caused delays in services and identified workload issues and a lack of capacity within CAMHS as a key source of delay in families receiving support, by under just one third of the survey respondents ( $n=7$ out of 22). This was supported by five interviewees who reported an increase in the workload of CAMHS services within the last 12 months and highlighted how this had impacted on services for adopted children.

Four of the interviewees raised concerns that the CAMHS in their area were not offering specialists to address any attachment difficulties.

[CAMHS are] increasingly limiting their work to clearly identifiable mental health issues and they are not dealing with children with attachment difficulties and they are turning children away who have attachment difficulties (Interviewee seven).

Half of the practitioners interviewed in this study reported that improvements were needed in the availability of education support for adopted children. The interviewees specifically cited a need for education colleagues to help adopters obtain a statement of special educational needs, or to provide the appropriate support within schools to address emotional or behavioural difficulties. Furthermore, three of the interviewees noted that improvements in schools are needed to understand and address the needs of adopted children within an education setting. However, four of the interviewees also acknowledged that a shortfall in the support offered within 
schools was often as a result of limited resources and a lack of capacity to provide additional support or services.

Three interviewees revealed that they carried out specific work in schools highlighting the needs of adopted children and their families. This work encompassed the circulation of information packs, undertaking workshops, creating links between school and other agencies (e.g. CAMHS) and working with staff to address the needs of individual children.

Three interviewees also reported that attempts had been made through service level agreements to improve the CAMHS provision available in their authority, and one interviewee reported that they were developing their own therapeutic provision:

What we'd like to do is we'd like to have a seamless model where we've also got a family therapist and a trauma therapist. We don't have those two things. What our intention is, is to create a multi-disciplinary team so that we can have those therapists working on a model that is geared towards adoption rather than generic issues (Interviewee one).

To conclude the most common support service available to adopted children and their families was counselling followed by general advice and information. These were also the most commonly requested services as reported by the survey respondents, however therapeutic support was also reportedly the service where there was the biggest gaps in service availability.

\section{Lack of resources for service provision}

As indicated earlier in this paper, in the methodology section, the interviews provided an opportunity to explore the availability of post adoption support services and their effectiveness and assessments of need, additional to what was captured in the survey. All of the practitioners interviewed reported that insufficient resources inhibit the provision of post adoption support. Half of the interviewees reported that the number of children being placed for adoption had increased in their local authorities in the last 12 months and that the increase is placing further strain on limited resources. In addition to this, interviewees expressed fears that the government's 
plan to reduce delays in the adoption process and increase the number of adopters, could make this issue worse:

I think it is all very well pushing for timescales to be improved and more adopters to come forward, but you know, if the support isn't there for the adopters in the long term, then you are not going to achieve the positive outcomes. The danger is, by moving things quicker we might end up with more families who need support (Interviewee eight).

Half of the interviewees also raised concerns about the capacity of all services working with adopted children to meet the complex needs, specific to this population. These interviewees noted that improved training may reduce the time taken to identify difficulties and put the appropriate services in place. One of the survey respondents summarised the issue:

[The] demands of increasing numbers is stretching us all. Concerns particularly for the future as the children we are placing nowadays are ever more complex and will need on-going support from all services at a time of reorganisations and budget cuts across all services including health and social care (Survey respondent three).

To add additional impediment three interviewees noted that while adopted children have a similar complexity of needs as looked after children, their status as adopted children means that they do not have access to some of the additional support mechanisms as their looked after peers, such as designated teachers for looked after children:

Children who are looked after do get additional resources and adopted children, don't. I think there needs to be better clarity about the fact that these children are likely to need an enhanced service [too] (Interviewee two).

To summarise it was reported that insufficient resources inhibited the provision of post adoption support and that this issue was exacerbated by the increase in numbers of adopted children. Their concerns were heightened following the 
government's plan to reduce delays in the adoption process and increase the number of adopters.

\section{Discussion}

At present the English government are prioritising all aspects of adoption including the recruitment of adopters, reducing delays in the adoption process and improving post adoption support (Department for Education, 2012a, 2012b). However, there are issues that require addressing to ensure that adoptive families get the support they require. These issues are discussed below.

\section{$\underline{\text { Assessments }}$}

This study found that it was common for adoptive families to request an assessment at crisis point rather than when issues first emerge. It was suggested that families would exhaust all other avenues first before approaching local authorities (LAs). Reasons for this included social services involvement being a last resort due to concerns that they would be perceived as failures - unable to cope with parenting their adoptive child, and the wish to be left alone to start family life without the continued involvement of their LA. This corresponds with previous research that suggests that adoptive families receive support at crisis point because they are concerned about the implications of social services involvement (Rees \& Selwyn, 2009; Pennington, 2012). However, the majority of children adopted will have been abused and/or neglected during childhood (Department for Education, 2014), which is likely to impact on their physical, cognitive, emotional and behavioural development (Maguire et al. 2015; McCrory et al., 2010; Veltman \& Browne, 2001; Brown et al., 1999). This means they will need additional support than that of routine parenting and that an assessment of needs is important.

\section{Availability of post adoption support}

This study found that the most common support service available to adopted children and their families was counselling followed by general advice and information. These were also the most commonly requested services by adoptive families. However the survey did not explore the availability of these services, i.e. accessibility, waiting times, costs etc. but interviews with practitioners revealed that the services that were 
most frequently requested by families were also reportedly the services where there were the biggest gaps in service provision, i.e. Child and Adolescent Mental Health Services and therapeutic services. This raises the issue of ensuring that post adoption service provision matches the needs of adoptive families. Especially considering that where adoptive families have been provided with support they have not always been provided with the support that they require most (e.g. therapeutic support) and that is most suited to their needs (Pennington, 2012). The Adoption Support Fund (ASF) could go some way to addressing the issue of access to therapeutic support as it allows, following an assessment of an adoptive family's needs, a LA to apply to the ASF for funding for therapeutic support. A recent evaluation of the ASF found that it expanded the provision of adoption support services and was viewed by families as enabling access to more support; and in some cases, seen as crucial in sustaining placements and keeping families together (Lewis et al., 2015). Normalising the need for post adoption support amongst adoptive families and continuation of adoption services may improve the extent to which adoptive parents feel able to request post adoption support through the ASF. In particular ensuring continued contact with adoption services which would help to embed the idea that support post adoption is normal and to be expected.

\section{Lack of resources for service provision}

Insufficient resources were identified as a key factor that inhibits the provision of post adoption support by interviewees in this study. The number of children being placed for adoption had increased in the LAs, in this study, placing further strain on limited resources and there were fears that the government's plans to reduce delays in the adoption process and increase the number of adopters, could make this issue worse. In addition, because LAs are not legally obligated to provide post adoption services, where resources are limited, post adoption support could be the first to be cut where finances are stretched. This is a particular concern considering that Pennington (2012) found that just under a third of adoptive parents that had needs identified went onto receive post adoption services identified in full. Normalising post adoption support would help adoptive families to see that the difficulties they are experiencing is to be expected and it would also ensure they are entitled to post adoption support services and not just the assessment of need. The Regional Adoption Agencies may 
go some way to address the issue of service provision. The exact model has not been prescribed but each regional adoption agency will include a range of services (e.g. recruitment, matching and support) and it is anticipated that this will contribute to ensuring that social workers have immediate access to a wider array of support services that are more accessible to adopted children and their families (see Department for Education, 2015b for further details).

Thus despite the government pledging increased funding for adoption support services, unless post adoption support is 'normalised', that is prospective adoptive parents are informed, that it is likely that their adopted child will need support in the future, it is a possibility that the take up of post adoption support could remain low.

\section{Conclusion}

To conclude, whilst there are a wealth of services in England that provide the type of support that would benefit adopted children and their families, the reality is that support is rarely continued post adoption. Those families that do require support often request it at crisis point, when they can no longer cope and the adoption is breaking down rather than when issues first emerge. If they do receive an assessment of need, identified needs cannot always be met due to resources and English LAs are not required by law to provide support. To ensure that adoptive families do receive the support they need, 'normalising' support and continuing it post adoption would be of value. The Adoption Support Fund and Regional Adoption Agencies may go some way to contributing to addressing these issues but there is a requirement for parents to be fully aware of what post adoption support is available for their adoptive family.

\section{References}

Biehal, N., Ellison, S., Baker, C. \& Sinclair, I. (2010) Belonging and permanence: outcomes in long-term foster care and adoption. British Association for Adoption and Fostering: London.

Bonin, E., Beecham, J., Dance, C. \& Farmer, E. (2013) Support for adoption placements: The first six months. British Journal of Social Work, 44, 1508-1525 
Brown, J., Cohen, P., Johnson, J.G. \& Smailes, E.M. (1999) Childhood abuse and neglect: Specificity of effects on adolescent and young adult depression and suicidality. Journal of the American Academy of Child \& Adolescent Psychiatry, 38, 1490-1496.

Creswell, J.W. (1998) Qualitative Inquiry and Research Design: Choosing Among Five Traditions. Thousand Oaks: CA, Sage.

Cooper, P.J. \& Johnson, S. (2007) Education. The views of adoptive parents. Adoption \& Fostering, 31, 21-27.

Department for Education. (2012a) An Action Plan for Adoption: Tackling Delay. Crown Copyright: London.

Department for Education. (2012b) Supporting Families that Adoption. Crown Copyright: London.

Department for Education. (2013) Further Action on Adoption: Finding More Loving Homes. Crown Copyright: London.

Department for Education. (2015a) Adoption Support Fund. Available at: http://www.adoptionsupportfund.co.uk/ Accessed: $1^{\text {st }}$ September 2015.

Department for Education. (2015b) Regionalising adoption. Crown Copyright: London.

Department for Education. (2016a) Children looked after in England (including adoption) year ending 31 March 2016. Crown Copyright: London.

Department for Education. (2016b) Department for Education - Adoption Reform Update: April 2016. Accessed on: $14^{\text {th }}$ November 2016. Available at: http://www.pacuk.org/department-for-education-adoption-reform-update-april-2016/

Harris, P. (2004) User views and experiences of post-adoption services A study of a regional post-adoption agency. Adoption \& fostering, 28, 50-60.

Johnson, R. B., Onwuegbuzie, A. J. \& Turner, L. A. (2007). Toward a definition of mixed methods research. Journal of Mixed Methods Research, 1, 112-133. 
Kieruj, N.D. \& Moors, G. (2010). Variations in response style behavior by response scale format in attitude research. International Journal of Public Opinion Research Vol. 22 No. 3

Lewis, J. \& Ghate, D. (2015) Adoption Support Fund: learning from the prototype. London: Department for Education.

McCrory, E., De Brito, S.A. \& Viding, E. (2010) Research review: the neurobiology and genetics of maltreatment and adversity. Journal of Child Psychology and Psychiatry, 51, 1079-95.

Maguire, S.A., Williams, B., Naughton, AM., Cowley, L.E., Tempest, V., Mann M.K., Teague, M. \& Kemp, A.M. (2015). A systematic review of the emotional, behavioural and cognitive features exhibited by school-aged children experiencing neglect or emotional abuse. Child: Care, Health and Development, 41, 641-53.

Miller, C. (1995) In-depth Interviewing by Telephone: Some Practical Considerations. Evaluation and Research in Education, 9: 29-38.

Neil, E., Cossar, J., Jones, C., Lorgelly P. \& Young, J. (2010) Supporting Post Adoption Contact in Complex Cases - Briefing Paper. Department for Education: London.

Pennington, E. (2012) It takes a village to raise a child: adoption UK survey on adoption support. Adoption UK: Banbury.

Randall, J. (2009) Towards a better understanding of the needs of children currently adopted from care. An analysis of placements 2003-2005. Adoption \& Fostering 33, 44-55.

Rees, C.A. \& Selwyn, J. (2009) Non-infant adoption from care: lessons for safeguarding children. Child: Care, Health and Development, 35, 561-567.

Rushton, A. \& Dance, C. (2002) Adoption support services for families in difficulty. A literature review and UK survey. London: British Association for Adoption \& Fostering.

Rushton, A. (2003) Knowledge Review 2: The adoption of looked after children: a scoping review of research. Social Care Institute for Excellence: London. 
Rushton, A. \& Monck, E. (2009) Enhancing adoptive parenting. A test of effectiveness. British Association for Adoption \& Fostering: London.

Selwyn, J., Sturgess, W., Quinton, D. \& Baxter, C. (2006a) Costs and outcomes of non-infant adoption. British Association for Adoption and Fostering: London.

Selwyn, J., Frazer, L. \& Quinton, D. (2006b) Paved with Good Intentions: The Pathway to Adoption and the Costs of Delay. British Journal of Social Work, 36, 561-576.

Selwyn, J., Wijedasa, D. and Meakings, S. (2014) Beyond the Adoption Order: challenges, interventions and adoption disruption. Research brief. London: Department for Education.

Shuy, RW. (2003) In-person versus telephone interviewing. In Inside Interviewing: New Lenses, New Concerns (eds. JA Holstein \& JF Gubrium), pp. 175-193. Thousand Oak: CA, Sage.

Stock, L., Spielhofer, T. and Gieve, M. (2016) Independent evidence review of postadoption support interventions. Research report. London: Department of Education.

Sturgess, W. \& Selwyn, J (2007) Supporting the placements of children adopted out of care. Clinical Child Psychology and Psychiatry, 12, 13-28.

Veltman, M. \& Browne, K. (2001) Three decades of child maltreatment research: Implications for the school years. Trauma, Violence \& Abuse, 2, 215-239.

Law:

The Adoption and Children Act (2002) 